\title{
Awareness and Practices of Women of Reproductive Age regarding the Use of Chlorhexidine for Newborn Cord Care in a Selected Community in Jos South Local Government Area, Plateau State, Nigeria
}

Bassi $\mathrm{AP}^{1}$, Ramyil MSC $\mathrm{MS}^{2}$, Isah $\mathrm{H}^{1}$, Auta $\mathrm{K}^{1}$, Ayodele $\mathrm{MJ}^{1}$, Bulus $\mathrm{FK}^{1}$, Dalyop $\mathrm{FK}^{1}$, Egbe $\mathrm{OS}^{1}$, Habila $L^{1}$

${ }^{1}$ Department of Community Medicine and Primary Health Care, College of Medicine and Health Sciences, Bingham University, Jos

${ }^{2}$ Departmen of Medical Microbiology and Parasitology, College of Medicine and Health Sciences, Bingham University, Jos.

Correspondence: M.S.C Ramyil; e-mail: crownramyil@yahoo.com Phone:+2348037884424

\begin{abstract}
Background: Neonatal mortality remains a public health concern in subSaharan Africa especially in Nigeria and poor cord care is a major contributor to the high neonatal mortality. The objective of this study was to assess the awareness and practice of Chlorhexidine cord care by women of reproductive age in Jos South Local Government Area of Plateau State.
\end{abstract}

Methods: This was a community based descriptive cross sectional study carried out among women of childbearing age in Lwellem Community of Jos South Local Government Area. A structured interviewer-administered questionnaire was used to obtain information from respondents who were selected through total population sampling. Data was analyzed using Statistical package for the Social Sciences version 20.

Results: Three hundred women with children aged less than 5 years were administered the questionnaire. Two hundred and ninety seven (99\%) were of low socio-economic status, 71 (23.5\%) were farmers, 75 (25\%) were traders and $60(20 \%)$ were not gainfully employed. One hundred and sixty seven (55.6\%) mothers were uneducated, $286(95.3 \%)$ attended antenatal care during their last pregnancy and 78 (26.0\%) were aware of Chlorhexidine use for newborn cord care with 89 (29.6\%) using it. One hundred and sixty eight (56.0\%) women practiced cord care to hasten falling of the cord and $85(28.3 \%)$ practiced it to prevent infection.

Conclusion: There is low awareness and use of Chlorhexidine for cord care in newborns. Women of reproductive age in this community should be educated on the use of Chlorhexidine cord care for newborns to reduce neonatal morbidity and mortality resulting from cord sepsis due to poor cord care practices.

Key word: Chlorhexidine cord care, Neonates, awareness, utilization

\section{Introduction}

Neonatal mortality has been an issue of public health concern in sub-Saharan Africa especially in Nigeria though over the recent years, there have been declines in neonatal mortality rates. ${ }^{1}$ Globally, neonatal mortality rate fell from $58 \%$ to $47 \%$ between 1990 and 2015 and infection accounted for $13 \%$ of the three million 
newborn deaths that occurred. ${ }^{2,3}$ Infections $(36 \%)$ have been reported to be the major cause of neonatal death and neonatal deaths account for $40 \%$ of deaths under the age of 5 years worldwide. ${ }^{4}$ This is more so in northern Nigeria where neonatal mortality stands at 44/1000 live births. ${ }^{5}$

The three major causes of neonatal death (infections, complications of preterm birth, and intrapartum related neonatal deaths) account for almost $90 \%$ of all neonatal deaths. ${ }^{6}$ To curb this trend in developing countries, the World Health Organization (WHO) in 2013 enlisted the use of antiseptic solution as means of clean cord care practices to reduce neonatal mortality and morbidity. ${ }^{6,7}$ Studies across the globe and particularly in sub-saharan Africa showed Chlorhexidine, when applied to the umbilical cord, is effective and efficient in reducing neonatal sepsis in high-risk settings, resulting in over $68 \%$ reduction in severe infection and a $23 \%$ reduction in all cause neonatal mortality. ${ }^{(8,9)}$

In 2016, a community based randomized trial was conducted in Tanzania to compare the use of Chlorhexidine for cord care with dry cord care in babies between $1-48$ hours old. The result showed that the neonatal mortality rate was not significantly lower in the Chlorhexidine group than in the dry cord care group. ${ }^{10}$ However, in another study in 2013 involving the distribution of Chlorhexidine in Sokoto State Nigeria, $99.97 \%$ of newborns who received chlorhexidine cord care and were followed up survived past 28days. ${ }^{11}$ In 2015 , another study conducted in Benin City, Edo State evaluated the content of health education on cord care given to mothers at various health facilities and found that health education on cord care was lacking in some of the health care centers; and even when available, the content may not be evidence-based. ${ }^{12}$
The hygienic practice of cord care is mainly done to hasten the separation of the umbilical cord and prevent sepsis within the first few days of life. However, studies have revealed that normal cord separation time may extend for as long as 28 days in some cases. ${ }^{13}$

Chlorhexidine was first introduced in Nigeria through the USAID/TSHIP project in Sokoto and Bauchi States and it recorded a $17 \%$ and $24 \%$ reduction in neonatal morbidity and mortality rates. ${ }^{14}$ The Federal Government of Nigeria developed a framework for its scale up in 2016 with the support of National Primary Health Care Development Agency (NPHCDA) and Paediatrics Association of Nigeria (PAN). This is intended to guide programming, resource allocation and commitments to achieve the national objective of Chlorhexidine uptake of 52\% after the fifth year of national scale- up..$^{15-18}$

Neonatal sepsis and prematurity have emerged as principal challenges to reduction in neonatal mortality and morbidity. ${ }^{19}$ Poor hygienic umbilical cord care in the first week of life is a welldocumented risk factor that increases the likelihood of neonatal infections. ${ }^{20-22}$ The knowledge of women of reproductive age on good cord care is vital. Their awareness and use of chlorhexidine for cord care is imperative not only to scale up its use but also to reduce the high neonatal mortality in this environment. The objective of this study was to determine the awareness of Chlorhexidine and its use for newborn cord care by women of reproductive age in Jos South LGA of Plateau State

\section{Methods}

This was a community based descriptive study carried out among women of reproductive age in Lwellem villages of Tanchol ward, Gyel District, Jos South 
Local Government Area, Plateau State, Nigeria. A structured questionnaire adapted from USAID/TSHIP project 2013 - 2015 was used to obtain data on age, place of antenatal care and birth, treatment applied to the cord stump and the socioeconomic status of the mothers. A total population sampling was done. The minimum sample size was calculated using Taro Yamane formula with 95\% confidence interval shown below. ${ }^{23}$ $\mathrm{n}=\mathrm{N} / 1+\mathrm{N}(\mathrm{e})^{2} \cdot \mathrm{n}=3210 / 1+3210(0.0025)$ $3210 / 9.025=355.7$ or 356

The number of households in the study area was 703 according to Polio Supplemental Immunization Activities (PSIA) numbering with a total population of 3,210. Only 320 households after six visits were found to be open with women of child bearing age and entered by the researchers. Thus, 300 women of reproductive age with under-five children were reached from the households and had the questionnaire administered on them. The 300 questionnaires were entered into Microsoft Excel 2003-2007 and analyzed with Statistical package for Social Sciences (SPSS) version 20.

Ethical clearance and permission were obtain from the Bingham University Ethical Committee and relevant authorities at Lwellem settlement of Tanchol ward, Gyel district, Jos South Local Government Area of Plateau State, Nigeria.

\section{Results}

The socio-demographic distribution of mothers of under five children shows that the largest age group was between 25-29 years; $86(28.7 \%)$ and the lowest age group $45-49$ years; 9 (3.0\%). The respondents with primary education or below were $167(55.6 \%)$ while $133(44.3 \%)$ had secondary and above. Majority of the mothers were traders; $75(25 \%)$ and farmers; $71(23 \%)$. On the average, most $(51.7 \%)$ women in the community had had at least 4 deliveries. Table 1.

Two hundred and eighty six $(95.3 \%)$ mothers attended antenatal care but only $26.0 \%$ of them were aware of Chlorhexidine being used for cord care. Most; 168 (56.0\%) mothers practiced cord care for the purpose of hastening falling off of the cord and only $85(28.3 \%)$ of the mothers practiced cord care to prevent infection. Most of the women in the community applied some substances other than Chlorhexidine $(29.9 \%)$ to clean the cord stump immediately after delivery. Table 2. Table 3 shows 29 (87.9\%) of the 33 respondents who had in-depth knowledge of Chlorhexidine used it for new born cord care compared to $12(26.7 \%)$ of the 45 women who lacked indepth knowledge of chlorhexidine but used it for cord care. This difference was statistically significant $(\mathrm{p}=0.00001)$ 
Table 1: Socio-demographic characteristics of respondents

\begin{tabular}{lrc}
\hline Characteristics & Frequency $(\mathbf{n}=\mathbf{3 0 0})$ & Percentage \\
Age group (years) & & 23.7 \\
\hline $15-24$ & 71 & 51.0 \\
$25-34$ & 153 & 22.3 \\
$35-44$ & 67 & 3.0 \\
$45-49$ & 9 & \\
Educational level & 28 & 9.3 \\
None & 139 & 46.3 \\
Primary & 117 & 39.0 \\
Secondary & 10 & 5.3 \\
Tertiary & & \\
Occupation & 60 & 20.0 \\
House wife & 3 & 1.0 \\
Civil servant & 75 & 25.0 \\
Trading & 71 & 23.7 \\
Farming & 41 & 13.7 \\
Artisan & 50 & 16.7 \\
Others & & \\
Antenatal attendance & 286 & 95.3 \\
Yes & 14 & 4.7 \\
No & & \\
Parity & 102 & 34.0 \\
1-2 & 104 & 34.6 \\
3-4 & 94 & 31.4 \\
5 \& above & &
\end{tabular}

Table 2: Awareness and practice of respondents to Chlorhexidine for Cord care Awareness

\begin{tabular}{llrr}
\hline Awareness of Chlorhexidine & & $\begin{array}{r}\text { Frequency } \\
\mathrm{n}=300\end{array}$ & $\begin{array}{r}\text { Percent } \\
(\%)\end{array}$ \\
\hline Heard of Chlorhexidine & Yes & 78 & 26.0 \\
& No & 222 & 74.0 \\
Reason for Cord care & To prevent infection & 85 & 28.3 \\
& To facilitates falling off of the cord & 168 & 56.0 \\
& To dry off the cord & 40 & 13.3 \\
& To prevent bad odour & 7 & 2.3 \\
Practice of cord care & & 5 & \\
No. of times substance is & Once a day & 127 & 4.7 \\
applied per day & $<3$ times a day & 165 & 55.3 \\
& $>3$ times a day & 3 & 1.0 \\
\hline
\end{tabular}


Table 3: The relationship between knowledge and practice of Chlorhexidine for cord care In-depth knowledge of chlorhexidine Practice of chlorhexidine cord care $\mathrm{X}^{2} \mathrm{p}$-value

\begin{tabular}{lrrrrr}
\hline & Yes (\%) & No (\%) & Total & 28.6 & $<0.001$ \\
Yes (\%) & $29(87.9)$ & $4(12.1)$ & 33 & & \\
No (\%) & $12(26.7)$ & $33(73.3)$ & 45 & & \\
Total & $41(52.7)$ & $37(47.3)$ & 78 & & \\
\hline
\end{tabular}

\section{Discussion}

The socio demographic data from women of Lwellem community showed the age group 25-29 years had the single highest number followed by the 30-34 years age group. However, mothers at the extremes of the reproductive age group (15-19yrs, $35-49 y$ rs) make up thirty percent of mothers of under five children in the community. This is similar to findings from the National Demographic and Health Survey (NDHS) report of 2013, which showed that in Nigeria, the proportion of mothers of under five children in the extreme groups of reproductive age is smaller than the proportion in the age group of 25-29 years, which results in decline in fertility ${ }^{17}$. Education plays a pivotal role in the knowledge and understanding of childcare. Our study showed that $55.6 \%$ of mothers of under-five children were of low educational level and is in keeping with studies conducted Nepal, Pakistan and Nigeria which showed that educational levels are low in women and this places them at a distinct disadvantage compared to men. Hence, this may in turn lead to a high neonatal mortality and morbidity. ${ }^{24,25}$,

${ }^{26}$ Occupation revealed that majority of respondents did not engage in any income generating activities. This agrees with the report of the NDHS 2013 which showed that only $45 \%$ of women in agricultural occupation were paid in cash/money while others were paid in kind or not paid at all. ${ }^{16}$
Thus, the women have an economic base that is too weak to provide the required resources for holistic care of their neonates leading to increased neonatal morbidity and mortality. ${ }^{17}$

Data analyzed on the parity of the mothers of under five children in the Lwellem community showed that the average number of children born to one woman is 4 which is lower than the total fertility rate (TFR) for Nigeria as recorded by NDHS $2013 .^{16}$ Higher number of deliveries $(>5$ pregnancies) carry much obstetric complications, hence for the $31.3 \%$ grand multiparous women of reproductive age, this raises the concern of maternal mortality and morbidity in the community. ${ }^{17}$ Knowledge of mothers on neonatal and childcare is essential for their proper growth and development. Women are expected to have information and skills for newborn care and recognition of neonatal danger signs during the neonatal period. In this study, a large majority of the women in the Lwellem community attended ANC during their last pregnancy. This is not in agreement with findings from the 2008 NDHS reports, which showed that in north eastern region, only between $16-58 \%$ of pregnant women received antenatal care from skilled provider.

It is recommended that Chlorhexidine be applied to the cord for all births irrespective of where childbirth takes place. However, in our study, three quarters of the respondents had not heard 
about Chlorhexidine as only $26.0 \%$ of the mothers had ever heard about the use of Chlorhexidine for cord care. This correlates with findings from a study conducted by TSHIP Final Dissemination Meeting in 2015, which showed that in Nigeria, coverage for Chlohexidine remains low with national coverage significantly under $5 \% .{ }^{14,27,28}$ We can infer that knowledge of the goal standard of cord care (Chlorhexidine gel/ solution) is poor in this community. This could increase the risk of neonatal morbidity and mortality as various studies conducted in developing countries have shown that chlorhexidine antisepsis interventions may improve neonatal health ${ }^{16,17,18,29}$. However, a study conducted in Benin City in 2015 on cord care education given at antenatal clinics showed that health education on cord care is lacking even among well-educated health care workers. ${ }^{12}$

This study found that majority of the mothers applied substances such as saltwarm water, Shea butter, Savlon/gentian violet, vasline etc. to facilitate falling off of the cord implying that majority of the women were more concerned about the cord falling off than preventing infection of the cord. The belief is common in many cultures that the cord should not dry so the practice of applying substances to the cord stump aims to make it soft allowing it to separate and heal easily and quickly. ${ }^{30}$ There were similar findings seen in rural Uganda in 2008, Ghana in 2005 and Nigeria in 2010 where these substances are believed to help the cord to dry and separate faster within 3 days and save the neonate from "evil eye" which they believe causes neonatal deaths. ${ }^{28,29,30}$ Hence, from this study, the practice of women in the Lwellem settlement on cord care is poor. This may be the result of poor or inadequate knowledge on cord care practices immediately after delivery. Cord care plays a major role in causing neonatal morbidities and mortalities. ${ }^{31}$

Chlorhexidine is poorly used for cord care in this community, meaning that many of the substances and methods used for cord care are based on traditional beliefs which are often interwoven with witchcraft, magic and taboo as reported in the LiST model, 2010. Here women were found to use charcoal or cow dung to dress the umbilical cord of neonates. ${ }^{32}$ A study conducted in Uganda showed that over $50 \%$ of the mothers applied various substances to the cord stump of their babies to quicken the healing. ${ }^{33}$ This agrees with our study which showed mothers practice cord care to facilitate drying off of cord. However, only a few of the mothers in this study practiced cord care to prevent infections. $^{33}$

\section{Conclusion}

This study found low awareness and poor utilization of Chlorhexidine for cord care in neonates among mothers of reproductive age in Lwellem Community. Women of reproductive age should be educated on the importance of the use of Chlorhexidine gel/solution for the cord care of their neonates.

\section{Acknowledgement}

The authors are grateful to the participants who consented and provided the information needed for this study. We also thank the community leaders for their commitment and sacrifices in ensuring that their community participated in this study.

Conflict of interest: The authors declare that there is no conflict of interest of any form. 


\section{References}

1. Lawn J, Mongi P, Cousens S. Africa's newborns-counting them and making them count Opportunities for Africa's Newborns 1-12 https://www.who.int/pmnch/media/p ublications/aonsection_I.pdf.Access ed 8 April, 2018.

2. United Nations Inter-agency Group for Child Mortality Estimation, Levels and Trends in Child Mortality: Report 2014.. Accessed 23 April, 2018.

3. Saleh JA, Nemecek J, Jones C. Impact of hygienic caring of the umbilical cord in the prevention of neonatal tetanus. Nig J Paediatr 2005; 32:19-25.

4. Imtiaz J, Hillary H, Sohail S, Amna Z, Naushaba M, Omrana P et al Neonatal mortality, risk factors and causes: a prospective population-based cohort study in urban Pakistan. Bulletin of the World Health Organization 2009;87:130-138. doi: 10.2471/BLT.08.050963. Accessed 23 April, 2018.

5. Liu L, Johnson HL, Cousens S. Child Health Epidemiology Reference Group of WHO and UNICEF. Global, regional and national causes of child mortality: 2012;379(9832):2151-2161.

6. Demis B, Hanna G. Level of Knowledge and Associated Factors of Postnatal Mothers' towards Essential Newborn Care Practices at Governmental Health Centers in Addis Ababa, Ethiopia Hindawi Advances in Public Health Volume 2018, Article ID 8921818, pp1-10 https://doi.org/10.1155/2018/892181 8. Accessed 8 April, 2019.
7. World Health Organization (WHO) Recommendations on Postnatal Care of the Mother and Newborn, 2013. November 17 2015.

http://apps.who.int/iris/bitstream/ 10665/97603/1/9789241506649 eng.pdf. Accessed 23 April, $201 \overline{9}$.

8. Hodgins S, Pradhan YV, Khanal L, Upreti S, Naresh PKC. Chlorhexidine for umbilical cord care: game-changer for newborn survival? March 2013 Global Health: Science and Practice 1(1):5-10 DOI:10.9745/GHSP-D12-00014

9. Imdad A, Mullany LC, Baqui AH, Arifeen SC, Tielsch JM, Khatry SK et al. The effect of umbilical cord cleansing with chlorhexidine on omphalitis and neonatal mortality in community settings in developing countries: a metaanalysis. BioMed Central Public Health 2013, 13(Supp13):S15 http://www.biomedcentral.com/14 71-2458/13/S3/S15

10. Sunil S, Usha D, Said MA, Arup D, Saikat D, Shaali MA et al. Efficacy of chlorhexidine application to umbilical cord on neonatal mortality in Pemba, Tanzania: a community-based randomised controlled trial. Lancet Glob Health 2016; 4(11):e837- 44

11. Molly C, Zulfiya C, Olugbenga O, William S, Kamil S, Nosa O. A case study of community-based distribution and use of Misoprostol and Chlorhexidine in Sokoto State, Nigeria. Global Public Health, 2016 http://dx.doi.org/10.1080/17441692. 2016.1172102. Accessed 23 April, 2019.

12. Abhulimhen-Iyoha BI, Ibadin 
MO. Cord care education and its content given to mothers at antenatal clinics in various health facilities in Edo state, Nigeria.

Sahel Med J 2015;18:129-33.

13. Mukhtar-Yola M, Iliyasu Z, Wudil BJ. Survey of Umbilical Cord care and Separation time in Healthy Newborns in Kano. Nigerian Journal of Paediatrics, 2011;38 (4):175 -181

14. TSHIP Final Dissemination Meeting. DHS 2013; PATH, "Market Research for 7.1\% Chlorhexidine Digluconate: Nigeria," Nov. 2014; Stakeholder interviews.

15. Federal Ministry of Health, Nigeria $(\mathrm{NFoH})$. National Strategy For Scale-Up Of Chlorhexidine in Nigeria 2016

16. Mullany LC, Darmstadt GL, Tielsch JM. Safety and impact of chlorhexidine antisepsis interventions for improving neonatal health in developing countries. Pediatric Infectious Disease Journal 2006; 25 (8):665-675.

17. National Population Commission (NPC) [Nigeria] and ICF International. Nigeria Demographic and Health Survey 2013. Abuja, Nigeria/Rockville, MD: 2014 NPC/ICF International.

18. Segrè S, Coffey P, Metzler M, Villadiego S, Brandes N, Hodgins $\mathrm{S}$, et al. Chlorhexidine for umbilical cord care. A case study prepared for the UN Commission on life-saving commodities for women and children. February, 2012. Available from: http://www. pdf.usaid.gov/pdf_docs/pnady705 .pdf accessed 28 April 2018

19. Abegunde D, Orobaton N,
Sadauki H, Bassi A, Kabo I A, Abdulkarim M. Countdown to 2015: Tracking Maternal and Child Health Intervention Targets Using Lot Quality Assurance Sampling in Bauchi State Nigeria. PLoS ONE10(6):e0129129.doi:10.1371 /journal.pone.0129129. Accessed 23 April, 2018.

20. Mairo AB, Merrill M, Emmanuel AA, Kokila L. Paediatric Surgery: A Comprehensive Text for Africa, Global Help: Health Education Using Low-Cost Publications, Omphalitis Chapter 20 2011, volume 1:124-128

21. Pezzati M, Biagioli EC, Martelli E, Gambi B, Biagiotti R, Rubaltelli FF. Umbilical cord care: the effect of eight different cord-care regimens on cord separation time and other outcomes. Biol Neomate. 2002 Jan;81(1):38-44.

22. Lawn JE, Blencowe H, Oza S, You D, Lee AC, Waiswa P et al. Every Newborn: progress, priorities and potential beyond survival. Lancet. 2014; 384(9938):189-205. doi: 10.1016/S0140-6736(14)60496-7. Epub 2014 May 19.

23. Taro Y. Statistics, An Introductory Analysis, 2nd Ed., 1967. New York: Harper and Row.

24. Pawan A, Vishnu K. The effect of mother's educational status on early initiation of breastfeeding: further analysis of three consecutive Nepal Demographic and Health Surveys. Obstet Gynecol Neonatal Nurs 2015; 28:501-6.

25. Soofi S, Cousens S, Imdad A. Topical application of chlorhexidine to neonatal 
umbilical cords for prevention of omphalitis and neonatal mortality in a rural district of Pakistan: a community-based, clusterrandomised trial. Lancet 2012;379 (9820):1029-1036.

26. National Demographic and Health Survey [NDHS] reports, 2008. UNICEF 2009 publication.

27. Patricia Coffey: $7.1 \%$ Chlohexidine Digluconate for Unbilical Cord Care introduction and Scale up. PATH (Chlohexidine Working Group) 2016. http:/www.healthnewbornnetwork .org/issue/chlohexidine-forumbilical-cord-care. Accessed 18 April, 2019.

28. Waise P, Kaikoba S. Acceptability of Evidence Based Neonatal Care Practice in Rural Uganda: Implications for Programming. International nursing journal 2008; 2(2): 52 -54.

29. Darmstadt GL, Bhatta ZA, Cousens S, Adam T, Walker N, Bernis L et al Evidence based, cost effective inter-ventions; How many newborn babies can we save?. Lancet 2005; 365 (9463): 977-988. Accessed 23 April, 2018.

30. Okedo K, Nelson P, Lawal W. An Analysis of custom related to child birth. Tropical Medicine 2010; 25:172-176.

31. Herlihy JM, Shaikh A, Mazimba A, Gagne N, Grogan C, Mpamba $\mathrm{C}$ et al. Local Perceptions, Cultural Beliefs and Practices that Shape Umbilical cord care: A quantitative study in southern province, Zambia. PLos ONE 2013; 8(11): e79191. Doi:10.1371/journal.pone.007919 1. Accessed 3 Dec, 2018.

32. Blencowe H, Lawn J, Vandelaer J, Roper M \& Cousens S. Tetanus toxoid immunization to reduce mortality from neonatal tetanus. Int J of Epid. 2010; 39:102-109.

33. Kayom VO, Kakuru A, Kiguli S. Newborn Care Practices among Mother-Infant Dyads in Urban Uganda. International Journal of Pediatrics. Volume 2015, Article ID 815938. 